\title{
Willingness to Pay for Water Supply and Sustainability of Water Facilities in Niger Delta Communities.
}

\author{
MOLUNO, Shedrack Uwadinisu \\ Department of Business Administration \\ Novena University Ogume. Delta State. Nigeria. \\ Email: molunosh@gmail.com \\ Phone No: 08038773388 \\ OGWEZZY, Melody Diobodo \\ European Union - Assisted Niger Delta Support Programme \\ Water Board Building, Ministrty of Water Resources, \\ Okaka Yenagoa. Bayelsa State Nigeria. \\ mogwezzy@gmail.com \\ Phone No: 08036747012 \\ OSEAFIANA, Joseph Ofor \\ School of Business Studies, \\ Department of Human Resources Mnagement. \\ Delta State Polytechnic Ogwashi-Uku, Delta State. Nigeria. \\ Email: oseafiana.joseph.ofor@gmail.com \\ Phone No: 08039369093 \\ ESEDEBE, Joseph Ejime \\ Department of Business Administration \\ Novena University Ogume. Delta State Nigeria. \\ Email: esedebeje@gmail.com \\ Phone No: 070333292442
}

\section{ABSTRACT}

The study is on the effect of willingness to pay for water supply and sustainability water facilities in Niger Delta

| Communities carried out in extention and revalidation of an earlier study done by European Union - Assisted Niger Delta Support Programme (EU-NDSP). Nine self-selected small towns in two pilot intervention local government areas (Kolokuma-Opokuma and Brass LGAs) in Bayelsa state, Nigeria were used for the study. The study relied on UNICEF (2013) baseline survey which estamates the population of the two LGAs at 117,026. A sample of 660 respondents were initally sampled using Bill Godden (2004) formular for determination of sample size, out of which 610 were eventually used for the study. The reseach design adopted for the study is the survey design. One questionnaire was developed and validated from which copies were made and administered to 660 respondents out of which 610 were validly retrieved and formed basis for the study. Analysis of the questions was done majorly using simple percentages in contingency table format. One hypothesis was tested using Chi square $\left(\mathrm{x}^{2}{ }_{3}\right)$ at $5 \%$ level of significance. The Chi square calculated is 39.3 while the critical value is 7.185 . The result of the study shows that willingness to pay for waters supply affects the sustainability of water resources. The study also show a willingness to pay for water that shall be provided under the EUNDSP and other donor water schemes with about $85 \%$ acceptance. The study concludes that willingness to pay affects the sustainability of water facilities and there is willingness on the part of the communities to pay for water services under the EU-NDSP and other donor water supply scheme.The study recommends as follows: (1) Donor agencies should always ascertain the willingness of benefiting communities to contribute to the sustainability of project before intervention (2) That communities should be encouraged to pay for water supply to ensure sustainability of the water facilities and (3) from inception phase of the project, there should be active advocacy and sensitization of all relavant stakeholders on management for sustainability to enhance willingness to pay.

Keywords: Willingnes to pay, Sustainability, Self-sellected

Aims Research Journal Reference Format:

Moluno, Shedrack Uwadinisu, Ogwezzy, Melody Diobodo. Oseafiana, Joseph Ofor \& Esedebe, Joseph Ejime (2018): Willingness to Pay for Water Supply and Sustainability Water Facilities in Niger Delta Communities... Advances in Multidisciplinary \& Scientific Research Journal. Vol. 4. No.2, Pp11-18 


\section{INTRODUCTION \& LITERATURE REVIEW}

Before now water is seen as a free gift of nature, but today water though still a natural resource can no longer be said to be free. Water, particularly portable water requires enormous resources input with financial implication to produce against which backdrop it can no longer be seen as free gift of nature. Water is life and life without water cannot be imagined, this probably explains why governments at different levels, corporate organisations as well as local and international donor agencies have tried to provide portable water to enhance the wellbeing of the populace. In spite of this global awareness and efforts to tackle the problem of water, portable water still remains a global challenge. Water is a quencher of thirst, a grower of crops, a generator of power, fundamental to hygiene and basic natural resources vital for our daily existence. Water is necessary for human survival. Water is also a foundation for development. Without water, there can be no economic growth, no industry, no hydropower, no agriculture and no cities. Investing in water governance and infrastructure means investing in jobs, agriculture and food security, education, gender empowerment, environmental equity, as well as reducing infant mortality, improving health and a host of other factors that are commonly seen as the pre-requisites of progress (Water integrity Network, 2010). In developing countries like Nigeria and other less developed countries, provision of water facilities is often used as political bait and enticement get the support of the populace by individuals, political parties and governments during elections. Corporate organisations in pursuance of corporate social responsibility, community based organisations, non- governmental organisations as well as civil society organisations all embark on water facility projects. Most time these projects from the inception phase to delivery are carried out without sustainability plan and this has not helped both the givers and the receivers.

According to an Uzbek saying 'if you run out of water, you run out of life.' Some experts would say that those words seem more prophetic than proverbial. Each year about two million people die as a result of poor sanitation and contaminated water, and 90 percent of the victims are children (Awake, 2009). The irony in the social sectors is that the poor pay more attention to safe and clean water above all other government services-including primary healthcare and education. Access to clean water and sanitation are basic human rights that underpin health, education and livelihoods and form the first essential step in overcoming poverty. The future of our own life support systems depend upon wise water management for securing ecological integrity which is the cornerstone for sustainable development (World Water Development Report (UN,2009). Water is the millennium development goal (MDG) seven and according to WHO/UNICEF (2012) even though the water target of the MDG seven has been met, more than one tenth of the global population relied on unimproved drinking water sources. In access to safe water, there is huge disparity in coverage with only 61 per cent in sub-Saharan Africa while inequities existed within countries between the rich and poor and, between those living in rural and urban areas. WHO/UNICEF (2013) further note that, water quality and safety parameters were not available for monitoring, which could have reduced access based on presence of less than $10 \mathrm{CFU} / 100 \mathrm{ml}$ of water. By the end of $2011,83 \%$ of the population without access to an improved drinking-water source lived in rural areas.

As noted earlier conscious and consistent multi-level efforts have been on to bridge the demand and supply gap for water globally and in Nigeria in particular. These efforts do not seem to have yielded the needed result to increase the population with access to portable water. This nagging portable water problem in the Nigerian context in the opinion of the researchers may not be partly unconnected to the sustainability plan for water facilities which to a great extent depends on the willingness of communities to pay for water supply services. Interestingly in Bayelsa State for instance $82.11 \%$ of the respondents in a willingness to pay survey are willing to pay for water supply which tends to contradict the facts on ground. This study therefore seeks to find out the extent to which willingness to pay for water supply affects the sustainability water facilities in Niger Delta Communities using Bayelsa State as a case study.

\subsection{Objective of the Study}

This study seeks to find out the extent to which willingness to pay for water supply affect the sustainability water facilities in Niger Delta Communities.

\subsection{Research Question}

Does the willingness to pay for water supply have any significant effect on the sustainability water facilities in Niger Delta Communities?

\subsection{Research Hypothesis}

The willingness to pay for water supply do not have any significant effect on the sustainability water facilities in Niger Delta Communities. 


\section{WATER SITUATION IN NIGERIA}

Nigeria has an estimated population of 180 million (Vision, 20:2020, 2009) and the population with access to safe drinking water increased from $47 \%$ to $61 \%$ between 2008 and 2011, with a gap of $14 \%$ to meet the $75 \%$ target for Nigeria on the MDG target (WHO/UNICEF, 2013). On sanitation, Nigeria is 5th highest in hierarchy in Open Defecation practise, after India $(626 \mathrm{~m})$, Indonesia $(63 \mathrm{~m})$, Pakistan $(40 \mathrm{~m})$ and Ethiopia $(38 \mathrm{~m})$ despite the fact that about 12.37 million people gained access to improved sanitation between 1990 and 2008 (WHO/UNICEF, 2012). Based on available statistics, Nigeria did not achieve the MDGs sanitation target of $63 \%$ access to improved sanitation by 2015 as nearly 100 million people lacked access to improved sanitation, and a large portion of the population (34 million people) practice open defecation (WHO/UNICEF, 2013). In the Niger Delta where this work focuses, sustainability of water facilities remains a major challenge. Provision of water supply in this region had all along been seen as the responsibility of government with little or no payment of water rates. This has made it relatively difficult for the government to continue with this social function of water supply.

\subsection{The European Union-Assisted Niger Delta Support Programme (EU-NDSP-3)}

In 2013, the European Union budgeted the sum of $€ 65,8000,000$ for the Niger Delta Support Programme of which the EDF will contribute $€ 56,000,000$, the five participating Niger Delta States, the participating Local Government Areas (LGAs) and the benefitting communities will contribute $€ 9,200,000$ and UNICEF, $€ 600,000$ million. This was a grant from the EUto finance the European Union assisted Niger Delta Support Programme (EU-NDSP-3) in five Niger Delta States. The general objective of the Niger Delta Support Programme (NDSP) is to mitigate the conflict in the Niger Delta by addressing the main causes of unrest and violence: bad governance, youth unemployment and poor delivery of basic services. The Water and Sanitation component of the NDSP has 3 main objectives:

1. To improve policy, institutional, legal and financial framework in the water and sanitation sector

2. To support urban and small towns' sector institutions to deliver sustainable water supply services.

3. To support rural water sector institutions to deliver sustainable water supply and sanitation services.

The project is providing a technical assistance for the achievement of the first two objectives while the third which deals with water and sanitation in rural areas is implemented by UNICEF. Objective one focuses mainly in institutional reform of the water and sanitation sector, while two and three focuses on rehabilitation and or provision of new water infrastructure. The project covers the States of Akwa Ibom, Bayelsa, Delta, Edo and Rivers. Primarily, the project focuses on initiating a reform process in the water sector by developing Water Policy and Laws in those states where they do not exist. The project also works on development plans for the water service delivery agencies (Project Recipient Agencies) and develops capacity of beneficiaries through training, mentoring and execution of works. These works consist of small rehabilitation in urban areas and rehabilitation or construction of water supply schemes within 2 focal LGAs per participating States (EU-NDSP-3, 2013).

\subsection{Sources of Water in Bayelsa State}

Although WHO/UNICEF (2013) note that the population with access to safe drinking water increased from $47 \%$ to $61 \%$ between 2008 and 2011, with a gap of 14\% to meet the 75\% target for Nigeria on the MDG target, the situation in Bayelsa is not certain. In Brass and Kolokuma LGAs, different sources of water ranging from government, corporate organisations, individual, and donor provided boreholes are available and between $62 \%-66 \%$ of these are not functional. Others are hand pumps, river water, rainwater harvesting, hand dug well and water vendors. The quality of water from these sources are not good due to a number of reasons; gas flaring and other emissions from hydrocarbon exploration and exploitation activities, salt water intrusion, presence of iron and heavy metals in underground water (NDSP-3 SEA Report 2016) .

\subsection{NDSP Technical Assistance Team (NDSP-TAT)}

The NDSP-TAT comprises of three experts and a project assistant in each of the five intervention states: the Institutional, Policy and Governance Expert (IPE), the Water and Sanitation Engineer (WSE) and the Community Mobilisation Experts (CME). The TAT through the CME and in conjunction with the executives of the Water Consumers Association (WCA) embarked on aggressive community mobilization and sensitization in pursuance the statutory 5\% operation and maintenance (O\&M) fund to ensure sustainability of the water schemes under the NDSP progrmme and other existing water facilities. In pursuance of the second objective, a willingness to pay survey (WTP) was carried out in 2015 in the self-selected small towns in the two focal LGAs of the five intervention States, to ensure sustainability of proposed NDSP project and other existing water facilities. The result of that WTP shows that the community dwellers in all the NDSP intervention states are willing to pay for water as long as the water provided is regular and of a good quality. In Bayelsa State for instance $82.11 \%$ of the respondents in that survey are willing to pay water supply (NDSP-WTP, 2105). 
The NDSP also in 2016 carried out a water facility inventory in the five intervention States, the inventory report shows that $62 \%$ of the water facilities in the three self-selected small towns in Brass LGA were non-functional while in Kolokuma /Opokuma six self-selected small towns, $66 \%$ of the water facilities were non-functional.

\subsection{Formation and Institutionalisation of Water Consumers Association}

The NDSP places a lot of emphasis in the sustainability water facilities and to ensue this, the TAT formed the water consumer association in all the self-selected small towns in focal LGAs. The roles and responsibilities of the newly formed WCAs revolve around the day-to-day operation of the water facility for sustainability. The WCA is the equivalent of the water users association in Kenya and have remained an integral part of the activities of the NDSP including the WTP survey which they supported actively in the in the five intervention States. Community ownership and management of water facilities for sustainability is the major reason for the establishment of the WCA. To institutionalize and give life to the WCAs, all the WCAs in the self selected small towns under the NDSP programme are duly registered with WASH units of their respective LGAs. The WCAs have a dedicated bank account were the present 5\% O\&M counterpart fund is being lodged and future revenue accruing to water shall be lodged.

\section{METHODOLOGY.}

The methodology applied is a mixed one and it was carried out in three stages to elicit valid data used for the study (both qualitative and quantitative data). Stage one was mainly pre-field activities and focuses on developing the survey instrument (questionnaire construction), validity and reliability tests of the instrument and logistic arrangement for mobilisation to field. There was also sensitization and awareness creation among WCA executives / members and other stakeholders on the purpose for which this survey was carried. Stage two focused mainly on the actual data collection activities / field work. Questionnaire and interview administration, coding of interview responses, editing and retrieval of completed questionnaire were done in this stage. The third stage comprises of post-field activities; this stage involves data presentation, analysis, interpretation, findings and conclusions.

\subsection{Research Design}

Given the nature of this study, which requires collecting primary data from respondents through the use of questionnaire, the researchers adopted the survey design. This survey method facilitates a systematic study of the population of interest through the use of questionnaire and interview to generate valid and reliable data for analysis. Secondary data was also relied on in the study.

\subsection{Population of the Study}

The population of this study comprises of all the adult water consumers in the self-selected nine (9) small towns in the two (2) self-selected LGAs: Twon-Brass, Okpoama \& Odioama in Brass LGA and Igbedi, Kaiama, Odi, Okoloba, Sabagreia and Sampou in Kolokuma/Opokumma LGA The population of the two LGAs according to UNICEF(2013) base line survey is estimated at 117,026 .

\subsection{Sample Size Determination}

The sample size for the study was determined using Bill Godden (2004) formula for determination of the sample size. The formula can be used to determine the sample size for both infinite and finite population, but with slight modification in the case of finite population. Infinite population within the context of Godden (2014) formula is any population from 50,000 and above while finite population refers to any population below 50,000. The population of this study falls within Godden's classification of infinite population. The formula and its' application are stated as follows:

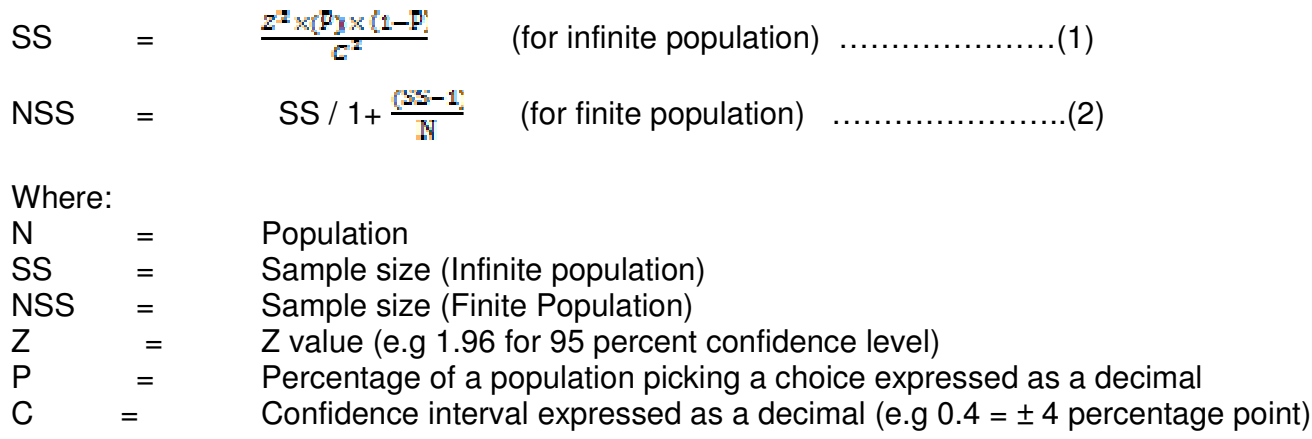

Source: Bill Goddon (2004).Book of Sampling (Statistics) Sample Size Formulas Williamgodden.com http://www.mathsfact.com/bookof-sampling-statistics-sample-size-formulas-williamgodden-com/Retrieved 27/09/2015 
In order to obtain a representative and useful sample, the foregoing parameters were applied with $10 \%$ added to the total sample size to allow for non-response, inappropriately filled or missing copies of questionnaires:

Population $(N)=117,026$; "Z" $=1.96 ; Z^{2}=3.8416$; "P"0.5 and "C" 0.04 ; the sample size "SS" is 600.25 . Detail of the calculation is as follows:

SS $=\frac{78416 \times[05) \times(05)}{0.0016}=600.25$ rounded down to 600 . Provision of $10 \%=600 \times 1.10=660$

\subsection{Sampling Technique}

Quota sampling technique was applied in the selection of samples for questionnaire administration. The towns were split into different units in line with the existing compound, village or quarter structure in the small town. The copies of the questionnaire were carefully administered such that there is adequate representation of the different groups in the small town.

\subsection{Sources of Data}

The data for study were drawn mainly from both primary and secondary sources. Data relating to the population and sampling frame were from secondary sources (UNICEF, 2013) while those elicited from the respondents through the use of questionnaire were from primary sources. The primary data particularly the ones elicited from the respondents through the use of questionnaire formed basis for the analysis.

\subsection{Description of Research Instrument}

The survey design was adopted for this study thus necessitating the construction and use of questionnaire. The questionnaire for the survey comprised mainly of closed ended questions. The questionnaire is split into three sections; personal characteristics, Social characteristics and sources of water. The questionnaire was subjected to validity and reliability tests as described herein below

\subsection{Validity and Reliability}

Validity test was carried out on the instrument (the questionnaire) to ensure that it measures what it is designed to measure. Content validity test was adopted for this study to ensure the questions contained therein are adequate both in content and scope.

The survey instrument was also subjected to reliability test to ascertain the degree of consistency of the measurement instruments if applied in the same circumstance and environment repeatedly overtime. The test retest method was applied and a correlation of 0.78 was obtained implying a strong measure of reliability.

\subsection{Questionnaire}

The final copies of the questionnaire was made ready after the pilot testing of the instrument since the measure of consistency obtained (0.78) from the test is acceptable. The questionnaire was deemed ready for distribution thus 660 ( Six hundred and sixty) copies were made in line with sample size for the survey and administered to the respondents.

The mode of distribution was by hand through the researchers and adhoc survey assistants that were trained by the researchers for the purpose. All completed questionnaire were retrieved by hand as well. A retrieval rate of $92 \%$ was achieved and a total of 610 copies of the questionnaire were retrieved and eventually became the actual sample size that formed basis for the anslysis in this survey. 


\section{PROCEDURE FOR DATA ANALYSES.}

One hypothesis was tested using Chi square $\left(\mathrm{x}^{2}{ }_{3}\right)$ at $5 \%$ level of significance. The Chi square calculated is 39.3 while the critical value is 7.185 . The result of the study shows that willingness to pay for water supply affects sustainabilty of water facilities. See table 1.1 below

Table 1.1 Calculated Value of $X^{2}{ }_{3}$ at $5 \%$ level of significance

\begin{tabular}{|c|c|c|c|c|c|}
\hline \multicolumn{6}{|c|}{ Observed Frequency (fo) } \\
\hline & SA & A & $\mathrm{D}$ & SD & Total \\
\hline Brass & 98 & 62 & 33 & 7 & 200 \\
\hline KOLGA & 204 & 146 & 31 & 29 & 410 \\
\hline Total & 302 & 208 & 64 & 36 & 610 \\
\hline \multicolumn{6}{|c|}{ Expected Frequency (fe) } \\
\hline & SA & A & $\mathrm{D}$ & SD & Total \\
\hline Brass & 99.01 & 68.2 & 20.98 & 11.80 & 200 \\
\hline KOLGA & 202.98 & 139.8 & 43.02 & 24.20 & 410 \\
\hline Total & 302 & 208 & 64 & 36 & 610 \\
\hline \multicolumn{6}{|c|}{$(\text { fo-fe })^{2}$} \\
\hline & SA & $\bar{A}$ & $\mathrm{D}$ & SD & \\
\hline & 1.02 & 38.44 & 3.14 & 401.5 & \\
\hline & 1.04 & 38.44 & 144.8 & 23.04 & \\
\hline \multicolumn{6}{|c|}{$(\text { fo-fe })^{2} / \mathrm{fe}$} \\
\hline & SA & A & $\mathrm{D}$ & SD & \\
\hline & 0.01 & 0.56 & 0.15 & 34 & \\
\hline & 0.005 & 0.27 & 3.36 & 0.95 & \\
\hline \multicolumn{6}{|c|}{$X^{2}{ }_{3}=\sum$ (fo-fe $)^{2} / \mathrm{fe}=39.3$} \\
\hline
\end{tabular}

Source: Survey Data 2018. 


\section{CONCLUSSION.}

The study concludes that willingness to pay for water supply guarantees the sustainability water facilities in Niger Delta Communities and also that the snall towns are willing to pay for water supply.

\section{RECOMMENDATIONS}

The study recommends as follows: (1) Donor agencies should always ascertain the willingness of benefiting communities to contribute to the sustainability of project before siting (2) That communities should be encouraged to pay for water supply to ensure sustainability of the water facilities and (3)from inception phase of the project, there should be active advocacy and sensitization of all relavant stakeholders on management for sustainability to enhance willingness to pay 


\section{REFERENCES}

1. SITAN, (2010) Situation Analysis (SITAN) of Water, Sanitation and Hygiene. Technical Report Submitted to UNICEF Abuja Country Office (Contract No: SSA/NGRA/ 2010/00002203-0). UNICEF Nigeria,.

2. Cairncross S, Bartram J, Cumming O, Brocklehurst C. (2010). Hygiene, sanitation, and water: what needs to be done? Plos Med 7(11):e1000365; doi:10.1371/journal.pmed.1000365 (Online 19 December 2017].

3. Jain N. 2011. Getting Africa to Meet the Sanitation MDG: Lessons from Rwanda. Washington, DC: World Bank Water and Sanitation Program. Available: http://www.wsp.org/sites/wsp.org/files/publications/wsp-rwandasanitation-lessons.pdf (Accessed 13 December 2017).

4. Naing, L., Winn, T., \& Rusli, B. N. (2006). Practical issues in calculating the sample size for prevalence studies. Archives of Orofacial Sciences, 1, 9e14.

5. NDSP, (2016). Strategic Environment Analysis Report of the Five Niger Delta Intervention States.

6. Nigeria Vision 20: 2020. (2009). Economic Transformation Blueprint. Federal Government of Nigeria.

7. Nigeria's Multi-indicator Cluster Survey, 2011

8. WHO (World Health Organization)/UNICEF.(2012). Progress on Drinking Water and Sanitation: 2012 Update. (Geneva and New York WHO/UNICEF Joint Monitoring Programme for Water Supply and Sanitation). Available: http://www.unicef.org/media/files/JMPreport2012.pdf (Accessed 13 December 2017].

9. WHO (World Health Organization)/UNICEF. (2013). Progress on Drinking Water and Sanitation: 2013 Update. (Geneva and New York WHO/UNICEF Joint Monitoring Programme for Water Supply and Sanitation). Available: http://www.unicef.org/media/files/JMPreport2013.pdf(Accessed 13 December 2017).

10. WHO (World Health Organization)/UNICEF. 2014. Progress on Drinking Water and Sanitation: 2013 Update. (Geneva and New York WHO/UNICEF Joint Monitoring Programme for Water Supply and Sanitation). Available: http://www.unicef.org/media/files/JMPreport2014.pdf (Accessed 10 December 2017).

11. WIN (2009), Water Integrity Network. Promoting Transparency, Accountability Participation and Anti-Corruption in the Water Sector. https://www.endwaterpoverty.org/news/win-member-spotlight

12. World Bank. 2013. How We Classify Countries. Available: http://data.worldbank.org/about/countryclassifications (Accessed 13 December 2017). 